\title{
Professor Ján Hovorka Birthday Centenary
}

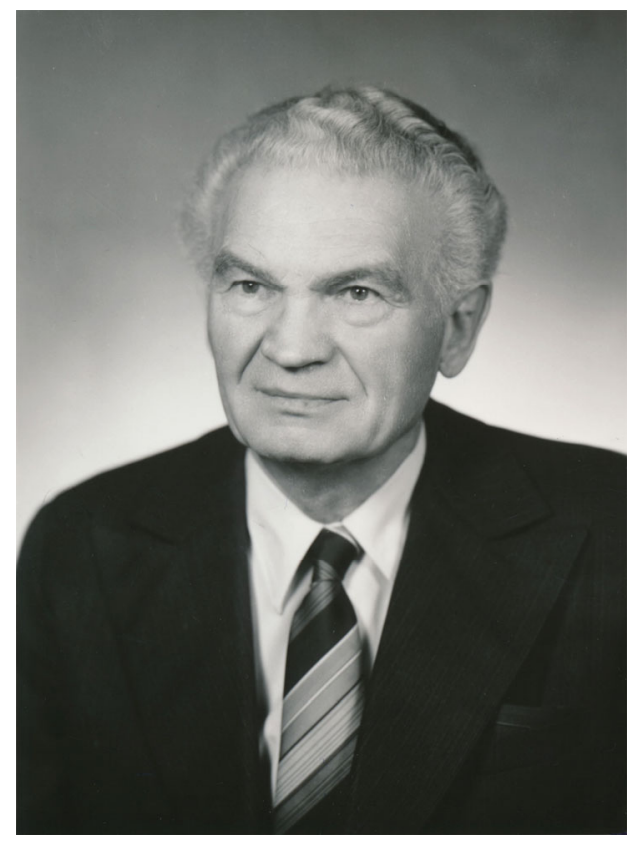

On the heels of the three major events, the $60^{\text {th }}$ anniversary of founding the Slovak Academy of Sciences and the Institute of Parasitology SAS (1953), and $65^{\text {th }}$ year of the existence of the University of Veterinary Medicine and Pharmacy in Košice (1949) comes another notable anniversary. February $9^{\text {th }}, 2014$ marks the birthday centenary of the late Prof. Ján Hovorka, Academician of the SAS and CSAS, who has laid the foundations for these institutions and promoted the publishing of several scientific journals and establishment of both national and international scientific societies.

Prof. Hovorka was born in Zvolen. Having graduated from the Veterinary College in Brno in 1939, after the creation of the first Slovak Republic he worked at the Ministry of National Defence in Bratislava, where he participated in the activities of veterinary management and supervised inservice training of veterinary service and food safety workers. In 1942, at the age of 28, he was appointed a stipendiary lecturer at the Department of Agricultural Engineering of the Slovak University of Technology in Bratislava. He contributed to the formation and acted as a head of the Department of Animal Anatomy and Physiology and worked as a lecturer in various clinical subjects. At the same time he served as a private veterinary practitioner. After his release from military service in 1944 he was appointed an associated professor.

In the post-war year of 1946, Prof. Hovorka decided to move his family to Košice, where he had played a crucial role in establishment of the College of Agriculture and Forestry Engineering and become its first Dean. A stormy post-war development of the agricultural sector had resulted in the establishment of another Slovak university - the College of Veterinary Medicine (CVM). Since its establishment on October $5^{\text {th }} 1949$, he served as its first Rector until 1952. Upon his initiation, several departments were set up, including the Department of Parasitology and Invasive Diseases, where he was serving as the Head and Professor of Parasitology until 1985. He was a long-term member of the Scientific Board of the CVM and worked in various committees and boards of advisors. He has been involved in the education of generations of veterinarians, who perceive him as highly respectable and demanding, yet human person who advised and supported his colleagues even after their graduation in tackling various issues of managing the serious animal parasitic infections.

Beside his university appointment, he was a member of the Presidium of the Slovak Academy of Sciences and Arts from 1950 to 1952 and he significantly participated in the establishment of the Slovak Academy of Sciences (SAS) as a head of the Subcommittee on the Biological and Medical Sciences. He had also prepared a proposal for establishment of an institution in Košice, focused on the research of human, animal and plant parasites. Both initiatives were successfully accomplished in 1953, when the SAS and Helminthological Laboratory were founded. The latter was then in 1955 renamed to Institute of Helminthology SAS and Prof. Hovorka acted as its head until 1988. Under his directorship, the institute outgrew its national framework and developed a broad international co-operation. In 1962-1965 he was a member of the Presidium of SAS and acted in many of its bodies and scientific boards, in the editorial boards and others. His scientific career was remarkable. In 1953 he was elected a corresponding member of SAS and CSAS (1967), academician of SAS (1964) and CSAS (1977). In 1961 he defended his thesis for the degree of Doctor of Science. He was also an honorary member of seven parasitological societies abroad.

One of his activities of a truly exceptional merit was initiating the research of helminths in Slovakia and its development at the international scale. It was rather a demanding task that required personal courage and foresight. A team of young scientists, who had been trusted by Prof. Hovorka, evolved a broadly composed research, focused on the helminths in Slovakia, including determining their diversity, ultrastructure, physiology and pathogenesis. A great attention was also paid to developing new drugs and more effective treatments and interventions against human, animal and plant helminth diseases. Many international co-operations have been established within a short period of time and at the same time a tradition of the International Helminthological Symposia has been established. Professional and often personal scientific relationships (even in the times when it was not supported by the state authorities) have resulted in the close co-operation with numerous universities and research centres abroad. Besides Prof. Hovorka's other activities, he was 
also a prolific writer and in the authorship or co-authorship he produced numerous textbooks and specialized publications and provided translated textbooks that were necessary for the university students. He is the author of a comprehensive monograph titled 'Helminths and Host-Helminth Relationships', several monographs and dozens of contributions published in scientific and professional journals. He established and edited the Veterinary Almanac (1952) and the Veterinary Journal (1953), a forerunner to the Slovak Veterinary Journal. He also stood behind the journal Helminthologia and for more than three decades acted as its Editor-In- Chief. And last, but not least, he served as a member of Editorial boards of seven national and international journals.

During more than 40 years of teaching Prof. Hovorka has paid a great attention to educating the new generation of researchers and improving their qualification. He educated 70 postgraduate students, and eight Doctor of Sciences dissertations were prepared under his supervision. As a member of Slovak Commission for Granting Scientific Degrees from 1964 to 1975 he participated in the co-ordination of postgraduate studies in Slovakia and acted as a member of accreditation commissions for biological and medical sciences.
Prof. Hovorka was one of the founding members of European Federations of Parasitologists and International Commission for Trichinellosis. The international prestige of the Institute under his leadership has enabled him and his colleagues to provide assistance in addressing human and animal parasitic infections in developing countries. During their long term stays in Cuba, Algeria and other African countries they had not only dealt with practical problems, but assisted in undergraduate and postgraduate education and developing scientific institutions. Similarly, he was active at home, too. During his college studies, he was a vice-chairman of the Tatran, Slovak Academic Association and the secretary of the Association of the Veterinary Students. Together with the prominent parasitologists he founded the Czechoslovak Society for Parasitology and acted repeatedly as its Chairman. He was also a co-founder and a long term Chairman of the Slovak Society of Veterinarians.

Prof. Hovorka's prolific professional, scientific and social life was cut short due to prolonged illness on November 15,2001 . On the occasion of any anniversaries of the organisations, societies and journals he has ever established or founded he is respectfully remembered by all of us. As his former students, colleagues and friends we are proud to commemorate the centennial anniversary of the birth of Prof. Hovorka.

Pavol Dubinský

Helminthologia, 51: 1, $77-78$ 